\title{
Familial occurrence of unilateral giant breasts in Nigeria: a possible new genetic entity
}

\author{
O A BADEJO
}

From the Department of Surgery, Anaesthesia, and Intensive Care, Faculty of Health Sciences, University of Ife, Ile-Ife, Nigeria.

SUMMARY Four cases of unilateral giant breasts from two unrelated families are described. Three i of the patients were managed surgically. It is speculated from a review of available published $\vec{i}$ reports that this condition may be genetic with an autosomal dominant mode of inheritance.

Sporadic reports of giant breasts exist in the literature and these have been described as ill-understood and often confused with chronic lymphoedema. ${ }^{1}$ To the best of our knowledge, familial occurrence of unilateral giant breasts has never previously been described. Observations in Ife, Nigeria have, however, shown that some forms of giant breast may be transmitted to offspring genetically. This condition develops very early in life and is distinct from breast hypertrophy which may develop during pregnancy and then fail to regress afterwards. Unilateral giant breast formation seen in four females out of a total of seven female children from two unrelated families seen in Ile-Ife, Oyo State, Nigeria forms the basis of this communication.

\section{Case reports}

The pedigrees of the two affected families are shown in fig 1 . The two families are not related and live on farms some 100 kilometres apart in the suburban area of Oyo State. There are two affected females in family A out of a sibship of four females and three males. None of the males was reported to have unilateral hypertrophy of the breast. Both parents in family $A$ are alive and are reported to be normal. In this family also, II.3 has had two children (III.1 and III.2) and the female (III.2) has already started showing early signs of unilateral breast enlargement at the age of 4 years.

In family $B$, there are three females in a sibship of six. Of the three females, two are affected (II.3 and II.6). There is no report of unilateral breast enlargement among the males in this family. Although the mother of the affected females in this family died 4

Received for publication 15 February 1983. Accepted for publication 3 August 1983.

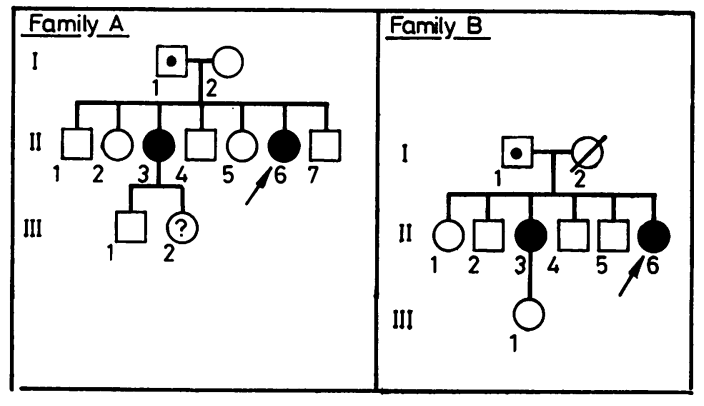

FIG 1 Pedigree of the two families.

years ago, the daughters were certain that their mother did not have a similar problem. One of the $\dot{\sigma}$ affected daughters in this family (II.3) has delivered a baby girl, who appears normal at present.

All four patients had noticed that the affected breast had developed around the age of 8 , much 0 earlier than the other unaffected side or those of the unaffected sisters. The affected breast had also 음 persistently grown bigger than the other one. Consequently, this feature had been a source of em- $\Omega$ barrassment to the patients, and they had always $N$ sought means to disguise the size in public. One of $N$ them claimed to have devised a method whereby the giant breast could be well 'packed' and thrown over her shoulder making it look very much like a handbag. The other two, visited in their homes, $\stackrel{0}{+}$ claimed to have been afflicted by gods and visited their village herbalists to no avail.

All patients claimed that the giant breasts were $\vec{\otimes}$ painful, itchy for periods ranging from 6 months to $\mathbb{D}$ 2 years before presentation, and non-discharging. They did not notice any relationship between the 
size of the breasts and the menstrual period, except that the aforementioned pains were intensified during the menstrual period.

All the patients involved in the series were generally fairly well nourished and well developed for their age. They did not look ill, were not markedly anaemic, and were afebrile and anicteric at the time of presentation. The significant findings were mainly in the breasts (fig 2). In all four instances the affected breast was on the left, and they were massively enlarged with the nipples between the level of the umbilicus and the anterior-superior iliac spines of the pelvis. The skin was normal in three cases while the fourth showed a $2 \times 1.5 \mathrm{~cm}$ oval hyperpigmented area around the mid-upper quadrant of the breast. There were multiple mobile peanut sized nodules each of about $4 \times 2 \mathrm{~cm}$ all over the breast in two sisters, while the other two from the second family had somewhat bigger nodular enlargements. All four cases had visible dilated veins located along the lateral aspect of the entire breast. The cervical and axillary lymph nodes were not enlarged. Two of the patients had bilateral nipple retraction while the other two had normal everted nipples. The right breasts were normal in all the patients.

INVESTIGATIONS

Three of the four affected patients were admitted and

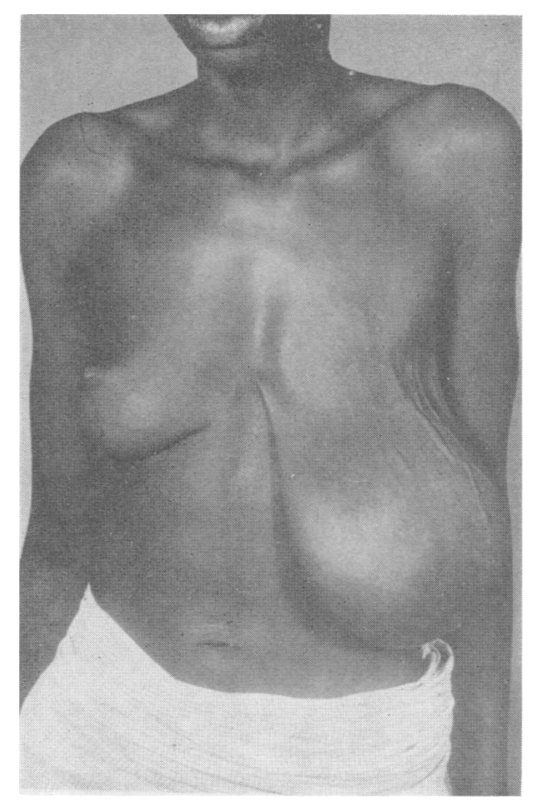

FIG 218 year old secondary school pupil with giant hypertrophy of the left breast. routine preoperative investigations were carried out. These included full blood count, serum protein electrophoresis, serum electrolytes, cholesterol, urea, creatinine, and urine analysis. They also had a Mantoux test, chest $x$-ray, and photographs before surgery.

The other side of our investigation was visiting the homes of the families to evaluate the surroundings and to carry out proper physical examination on other sibs and the one affected female who refused to be admitted to hospital for surgery.

\section{Results}

The full blood count, serum protein electrophoresis, serum electrolytes, cholesterol, urea, and creatinine were within normal limits. Stool examination for ova and parasites was negative and urine analysis and various radiological studies were within normal limits. The Mantoux test in all three cases was between 7 and $9 \mathrm{~mm}$. Investigations carried out around the homes of the affected families yielded nothing abnormal or different from all other families living in the same area.

The histology section showed large areas of fat cells compressing the breast lobules. There were large areas of hyalinisation in the stroma. No evidence of malignancy was seen in any of the sections.

The postoperative periods were satisfactory (fig 3). One of the patients required blood transfusion and two others had wound infection. One of these infections was so severe that the patient had to lose the nipple, despite a tolerable size of the reduced breast. This patient developed compensatory hypertrophy of the other breast within a year after surgery.

She is still under our observation with a view to

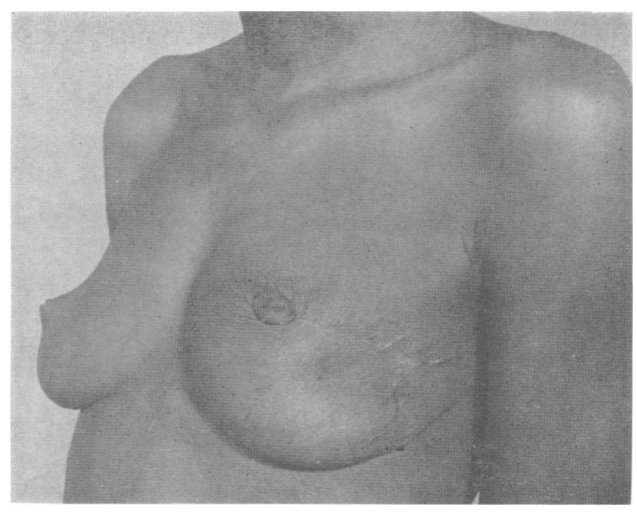

FIG 3 Side view of the 18 year old patient one year after surgery. 
having an implant in due course. The other two patients have done very well. One is still at secondary school and the other is the proud mother of a baby girl. She claimed that she has been able to breast feed her baby without any difficulty. All the patients are alive and well. The average stay in hospital was 2 weeks and the period of follow up for all of them ranged from 2 to 4 years.

\section{Discussion}

The familial occurrence of unilateral giant breast has not previously been reported. The condition as seen in Africa has been described by Davey ${ }^{1}$ as illunderstood and may be confused with chronic lymphoedema. Davey ${ }^{1}$ also stated that such a condition may develop during pregnancy and fail to regress afterwards. Two of the four cases reported here had never been pregnant and the other two patients noticed the breast enlargement long before child-bearing age. These features do not support Davey's suggestion and indicate that giant hypertrophy of the breast may be genetic and not just random. The observation that a 4 year old child of one of the affected patients already shows signs of early breast enlargement also seems to support this view.

It is also important to mention that this condition does not fit into any of the known syndromes of hemihypertrophy, ${ }^{23}$ because many organs and structures are usually involved in these syndromes.

The pattern of inheritance of this condition as revealed by the two pedigrees is difficult to ascertain. It is possible that this condition is the result of a rare autosomal recessive gene. If it is, then one would expect some males to be affected as well unless it is sex limited. However, the possibility that there might be direct transmission from mother to offspring (as in family A) may be against this proposition. An $X$ linked recessive gene can be dismissed on the basis of possible mother-to-daughter transmission. An $X$ linked dominant gene is a possibility, but when one considers the rarity of dominantly transmitted genes that are $\mathrm{X}$ linked ${ }^{45}$ this mode of inheritance seems unlikely. Besides this, one would have to postulate 'reduced penetrance' and 'sex limited' behaviour to accept this mode of inheritance.
It is also possible that the gene for unilateral giant $\stackrel{\mathbb{P}}{+}$ breast is an autosomal dominant one. This could $\vec{F}$ have arisen by spontaneous mutation, but if this were the case one would normally expect sporadic single cases rather than familial clustering as in both our pedigrees. The only genetic postulate that we need to make in order to accept an autosomal dominant mode of inheritance is 'sex limited कै inheritance'. In this case, we have to assume that the $\vec{\circ}$ male parent (I.1 in each pedigree) is the carrier of the gene, either by inheritance or spontaneous mutation, and because he is a male he would not be expected to express the gene. Half of his offspring would be expected to inherit the gene from him, of which only the female carriers of the gene would express the condition. This mode of inheritance appears to be the most plausible for the condition under consideration.

The author would like to acknowledge the constructive criticisms and advice given by $\mathrm{Dr}$ A B ScottEmuakpor and Professor $\mathbf{J}$ A Omene, both of the Department of Child Health, University of Benin, Benin City, during the revision of this manuscript. $\mathrm{He}$ is also grateful to the members of staff of the Medical Illustration Unit, Faculty of Health Sciences, University of Ife, Ile-Ife for their help and Mr I A Oyedola for typing the manuscript.

\section{References}

1 Davey WW. Companion to surgery in Africa. 1st ed. Edinburgh: Churchill Livingstone, 1968:165-73.

2 Gorlin RJ, Meskin LH. Congenital hemihypertrophy. J Pediatr 1962;61:870-9.

3 Wagner R, Kottmeier HL. Uber Hemihypertrophia und Hemiatrophia corporis totalis nebst spontane Extremitatengangrane bei Sauglingen in Anschluss zu einem ungewohnlichem Fall. Acta Paediatr 1938;20:543.

${ }^{4}$ McKusick VA. Mendelian inheritance in man. Catalog of autosomal dominant, autosomal recessive and X-linked phenotypes. 4th ed. Baltimore: Johns Hopkins University Press, 1975.

5 Vaughan V, McKay J, Behrman R. Textbook of paediatrics. 11th ed. London: Saunders, 1979:337-44.

Correspondence and requests for reprints to Dr O A Badejo, Department of Surgery, Anaesthesia, and Intensive Care, Faculty of Health Sciences, University of Ife, Ile-Ife, Nigeria. 